\title{
Artigo
}

\section{O queer enquanto enfoque zetético para refletir sobre o direito à educação}

El queer como um foco zetetico para reflejar sobre el derecho a la educación

The queer as a zetetic focus to bethink the right to the education

Le queer comme une approche zététique de la réflexion sur le droit à l'éducation

\author{
Alan Isaac Mendes Caballero \\ Ana Elisa Spaolonzi Queiroz Assis \\ Universidade Estadual de Campinas, Brasil
}

Recebido em: 31/07/2019

Aceito em: 28/08/2020

\section{Resumo}

A partir de uma discussão comparativa com uma literatura que relaciona gestão escolar a gênero na superação de desigualdades educacionais, encontramos nos princípios de gestão democrática e cidadania recomendações comuns para cumprir o direito à educação. Porém, ensaiamos uma zetética queer para desconfiar desse tipo de recomendação pedagógica por compreender que uma interpretação do direito à educação por um princípio da diferença sustenta uma orientação moral distinta ao afirmar a importância de valorizar a Moral da escola em virtude do Direito dos governantes, guiado pelo princípio da igualdade.

Palavras-chave: Gestão escolar. Direito à educação. Zetética. Queer.

\section{Resumen}

Partiendo de una discusión comparativa con una literatura que relaciona gerencia escolar a género en la superación de desigualdades educacionales, encontramos en los principios de gerencia democrática y ciudadenia recomendaciones comunes para 
cumplir el derecho a la educación. Todavia, ensayamos una zetética queer para desconfiar de este tipo de recomendación pedagógica al comprender que una interpretación del derecho a la educación por un principio de diferencia sostiene una interpretación moral distinta al afirmar la importancia de valorizar la Moral de la escuela frente al Derecho de los gobernantes, guiado por el principio de la igualdad.

Palabras-clave: Gerente escolar. Derecho a la educación. Zetética. Queer.

\section{Abstract}

Starting from a comparative discussion within a literature relating school management to gender for overcome educational inequalities, we found in the democratic management principle and citizenship the common recommendations to accomplish the right to education. However, we essayed a zetetic queer for suspect about this kind of pedagogic recommendation by the understanding that interpreting the tright to education under the difference principle sustain a distinct moral interpretation by affirming the importance to ameliorate the school Moral in view of the governors Right, guided by the equality principle.

Keywords: School management. Educational right. Zetetic. Queer.

\section{Rèsumè}

À partir d'un débat comparatif basé sur la littérature qui articule gestion scolaire et genre, en vue de surmonter les inégalités éducatives, on retrouve dans les príncipes de la gestion démocratique et de la citoyenneté des recommandations communes pour respecter le droit. Toutefois, on a essayé d'appliquer une zététique queer pour vérifier dans quelle mesure ce genre de recommandation pédagogique, donne une interpretation du droit à l'éducation en tant que principe de différence soutient l'orientation morale distincte en affirmant l'importance de valoriser la moral de l'école em raison du droit des gouvernants, guidé par le príncipe de l'égalité.

Mots-clés: Gestion scolaire. Droit à l'éducation. Zététique. Queer.

\section{Introdução}

Desde a década de 1990, presencia-se o avanço de reformas neoliberais na educação com a movimentação da Nova Direita (Oliveira et al., 2017). A partir delas, pode-se constatar um confronto entre um "Estado mínimo" e um "Estado provedor" pelo incentivo aos princípios de liberdade individual, livre mercado e propriedade privada. Estes seriam os eixos norteadores de um projeto político comprometido com a justiça social e redução de desigualdades. Desta maneira, as políticas sociais e fiscais de um Estado intervencionista seriam preteridas nos Estados Unidos de Ronald Reagan, na Inglaterra de Margareth Thatcher, no Chile de Augusto Pinochet e no Brasil de Fernando Henrique Cardoso (para dar alguns exemplos), em virtude da globalização dos mercados, de processos de desregulamentação e estabilidade monetária, soluções que, ao contrário de combater a intervenção do Estado, findam apenas por modificar a qualidade da intervenção e acentuar os níveis de desigualdade (Ramalho Jr., 2012). 
Simultaneamente ao período das reformas educacionais no Brasil, percebe-se o espírito democrático naqueles que viveram as marcas do regime ditatorial no país (ou conseguiam notá-lo) com início em 1964, de um enfrentamento ao comunismo que se estende para manter a ordem em sentido mais amplo, acrescentando-se o combate ao homossexualismo (entre outras desordens no espírito nacionalista) (Pinheiro, 2018). A Constituição Federal de 1988 (CF/88) (Congresso Nacional do Brasil, 1988) seria uma aposta política dos "representantes do povo brasileiro", ao menos no preâmbulo do documento. Esse mesmo espírito democrático irrompe na voz de movimentos sociais que lutavam por reconhecimento político do Estado, não somente no Brasil, mas no mundo. Por esta razão, a década de 1990 é também um período de busca por igualdade social, identificada nas agendas globais de gênero da Organização das Nações Unidas (ONU) e da Organização das Nações Unidas para a Educação, a Ciência e a Cultura (UNESCO) para diminuir os índices de desigualdade de gênero, incentivando países de todo o mundo a comprometerem-se com o direito à educação, sobretudo no aumento e na paridade do número de matrículas nas escolas, para torná-la, enfim, universal (Dias Jr. \& Caballero, 2020).

Ao menos no Brasil, essa luta estaria associada no campo da educação com o tema transversal Orientação Sexual, dos Parâmetros Curriculares Nacionais (PCN) (Secretaria de Educação Fundamental [SEF], 1997), para marcar um progresso educacional do país rumo a uma cidadania global do século XXI, para uma sociedade da inclusão. A transversalidade como mudança de paradigmas educacionais para uma educação integral de crianças e jovens é reforçada com a discussão de descentralização das decisões curriculares para os municípios e às Unidades Escolares dentro do sistema educacional, fortalecendo os princípios de igualdade na diferença propagados por ideais democráticos (Vianna, 2018). Assim, credita-se a essa via transversal a possibilidade de integrar a globalidade da nação à localidade das escolas, sem abrir mão das disciplinas obrigatórias que certificam o caráter do currículo.

Em artigos anteriores, operamos com a ideia de que o neoliberalismo de Estado só pode sustentar seus interesses democráticos levando-se em consideração a existência de uma democracia burguesa (Caballero, 2020). Com efeito, o direito à educação torna-se a propagação do conceito de aprender a aprender que sustenta uma cultura empreendedora preocupada com performances saudáveis e produtivas à manutenção do capital (Dias Jr. \& Caballero, 2020), o que se verifica também para políticas de diversidade sexual capazes de continuar normas de gênero para o governo sadio de uma população (Caballero, 2020). Porém, se existe alguma influência da população na criação de políticas, ela é improvável sem a interferência de governantes nesse embate político.

Defendeu-se, portanto, que a pretendida descentralização democrática sofre abalos contínuos pela necessidade de governos neoliberais em concentrar o poder por meio de práticas gerencialistas, o que significa lançar mão de mudanças curriculares, avaliativas,

3 - Linhas Críticas, Brasília, DF, v. 26 (2020), p. 3-18 
pedagógicas e didáticas, fazendo da gestão escolar a extensão de seus interesses (Ball, 1994). Em outras palavras, sob a roupagem de um discurso de incentivo à autonomia e liberdade às escolas seria possível conduzir uma performatividade de desempenho utilizando-se da responsabilização de determinados agentes pedagógicos para inculcar uma ética mercadológica nos corpos escolares, cuja tônica encontraria no sucesso individual e na concorrência uma explicação para a superação de desigualdades sociais, o que motiva a pensar os problemas educacionais como problemas de gestão.

Partindo de uma discussão comparativa que relaciona gestão escolar e gênero para a superação de desigualdades educacionais, apresentaremos de forma breve como o legalismo nas interpretações correntes para defesa do direito à educação requer uma sutil reformulação argumentativa na tentativa de evitar a lógica gerencialista. Baseamonos em uma zetética queer para repensar a compreensão usual de direito à educação valendo-se do princípio da diferença, de tal forma que estranhar as atividades de Estado seja necessário para agir com justiça no cotidiano escolar. Não tratamos aqui de propor a eliminação do Estado, mas desconfiar da democratização de suas estruturas, políticas, ações e decisões apenas porque proferem um discurso democrático (Gallo, 2018). Nossa ênfase em gestoras/es escolares permite explorar suas possibilidades de defender as crianças queer em um sistema educacional permeado por políticas neoliberais de controle e responsabilização que encontram no gerencialismo suas articulações primordiais para a produção e seleção de corpos capitalizáveis e a eliminação ou expulsão de corpos não capitalizáveis (Preciado, 2008/2018).

\section{Por que a zetética?}

Parece-nos adequado sugerir que o gestor escolar é não somente um agente encarregado de interpretar o direito à educação por meio de princípios de igualdade e diferença (Cury, 2002), mas também individualmente responsabilizado por suas decisões quando prevalece uma cultura empresarial nas redes políticas, ainda que exista uma equipe pedagógica. Esta atitude interpretativa consiste em uma forma de exteriorizar um sentido interiorizado ou o inverso. Para o primeiro caso, observamos um princípio relacionado ao juízo de valor a partir do qual tem relevância o trabalho de Simioni (2015) sobre a percepção seletiva do juiz. Para o segundo caso, espera-se a constituição de uma dialética das relações processuais, presente em Gomes (2011), denominada práticas e processos pelos quais organiza e estrutura-se competência, ética, valores e o trabalho esperado dos juristas.

Ainda com Simioni (2015), poderíamos trazer um valor positivo à interpretação da palavra pelas experiências contidas no mundo interno dos sujeitos, ao dizer que, sem elas, não seria possível interpretar coisa alguma, sem subjetividade não há objetividade - um sistema aberto. Gomes (2011) balanceia esta proposição a partir de suas próprias 
considerações sobre o assunto: espera-se a existência de conflitos por hegemonia e divergências nos sistemas políticos e jurídicos, pois a ideia de unidade só existe como pressuposição, exigindo investigações acerca dos processos que levam esses sistemas a se organizar com a coerência apresentada - um sistema fechado.

A abordagem zetética normativa permite uma discussão jurídica que se desprende da ideia de sistema fechado (Viehweg, 1953/2008; Assis, 2012). Theodor Viehweg entende que o direito, a despeito de possuir pontos de partida, não está preso a esses pontos, os quais podem e devem ser questionados. Diz-se que "o enfoque zetético revela-se como um saber especulativo, sem compromisso com a necessidade imediata (...) do direito. Pode-se considerar que ele implica um conhecimento teórico (desinteressado) e sem compromisso imediato com a ação." (Assis, 2012 p. 12).

Tendo tais diretrizes como base, somos incentivados por Silva e Wang (2010) a discordar das decisões majoritárias no campo do Direito, aí incluídas concepções sobre o direito à educação, uma vez que:

Sob o enfoque zetético as normas comportam pesquisas de ordem sociológica, antropológica, filosófica, histórica, etc. Nessa perspectiva o investigador (jurista, sociólogo) preocupa-se em ampliar as dimensões do fenômeno jurídico, sem limitar-se aos problemas relativos às decisões dos conflitos. Pode encaminhar sua investigação para os fatores reais do poder que regem uma comunidade; para as bases econômicas e os reflexos na vida cultural ou social e política; para o levantamento dos valores que orientam a ordem constitucional; para uma crítica ideológica do atual estágio dos diversos ramos do direito: penal, empresarial, ambiental, civil, tributário, etc. A investigação zetética não exerce exatamente um papel apaziguador no sentido de conceder total segurança à construção e à interpretação jurídica. Mais do que fornecer uma resposta para um determinado tema, cuida principalmente da tarefa de problematizá-lo. Assim ocorre com os temas ou problemas enunciados de forma mais genérica, por exemplo, a questão da justiça, da liberdade, da igualdade, do preconceito, da preservação do ambiente, da função social da propriedade, dos direitos humanos e sociais, etc. (Assis, 2012, p. 12).

Dentro do escopo aqui delimitado, utiliza-se a zetética para abrir o fecho interpretativo de epistemologias políticas correntes na temática da gestão educacional, espera-se com isso uma reviravolta estética na forma de conceber os princípios de igualdade e diferença para interpretar o direito à educação. As epistemologias queer, por sua vez, surgem como a instância que provoca novas percepções, desestabiliza, inventa, escapa à norma, sem a pretensão de chegar a algum lugar (Louro, 2004). Por ser aberto, consiste em premissas intermináveis do que são os corpos sexuados.

Já que "o zetético [...] desintegra, dissolve as opiniões, pondo-as em dúvida" (Ferraz Jr., 1968/2003, p. 41), exaltando o devir-ser ao dever-ser, o queer não pode ser diferente, pois é uma hipótese infinita de infinitas hipóteses. Assim o queer emerge no direito zetético seguindo a face mais coerente para esse direito, o da "sustentação moral da indignação e da rebelião" (Ferraz Jr., 1968/2003, p. 31). Se a zetética é queer, o será mantendo o compromisso com a desconstrução do conhecimento (Louro, 2001): trazer pontos de vistas antes ignorados para reinterpretar um objeto que apresenta alguma coerência e articulação entre juízos de valor. 
É na solidificação dos signos que concebemos o estranhamento como atitude necessária para rever concepções naturalizadas acerca do "lugar comum", pois duvidar de noções inquestionáveis põe à prova a naturalidade dessas questões. Afinal, sendo o gerencialismo um dos efeitos do neoliberalismo para a educação, há riscos jurídicos-políticos de se utilizar das interpretações correntes do direito à educação para incluir as crianças queer à sociedade.

\section{Estranhando a gestão escolar}

Administração escolar é o termo que antecede gestão escolar no Brasil. Nele, é percebida a influência das Teorias Gerais de Administração, cujo caráter científico investiga as condições de aperfeiçoamento da atividade de gestão em um momento em que as experiências de homens na direção se valiam de um toque pessoal (ou empreendedor). Em Santos (2018), encontramos elementos a partir das principais referências históricas sobre a administração escolar para pensar seus prováveis objetivos no Brasil: a) encontrar unidade no trabalho desenvolvido nas escolas; b) aumentar o desempenho de estudantes para atingir resultados; c) contribuir para a economia, o desenvolvimento e o progresso do país; d) organizar coisas e pessoas em operações para a condução dos fins determinados. Sendo informar-se, decidir, coordenar, dirigir, programar, planejar, comunicar, inspecionar, controlar e pesquisar, algumas das atividades esperadas de um administrador escolar, agente que deve compreender a escola como um conjunto organizacional.

Em resumo, um administrador escolar desenvolve princípios e métodos para maximizar a produção escolar com o menor custo possível. Um contraponto à administração geral aparece com a corrente do marxismo crítico, o qual nomeia este "aperfeiçoamento" de tecnicismo por consistir, grosso modo, na oferta de técnicas de administração para aumentar a eficiência escolar a partir de análises internas da escola e produzir, assim, quadros profissionais para atuarem no desenvolvimento do Brasil. A partir de então, a gestão democrática mostra-se um ideal a ser perseguido, o que exige a participação da comunidade nas decisões da escola para contrapor práticas autoritárias e concentradoras de poder, promovendo liberdade, emancipação, inclusão, justiça, igualdade e apropriação de novos saberes culturais para seu território (e seu currículo).

Santos (2018) também aponta que, na década de 1980, a gestão democrática consolidase como um princípio que recupera a dimensão pedagógica e política da atividade gestora (dividida em supervisão, secretaria, direção e coordenação) para superar desigualdades sociais no cotidiano escolar, contribuindo para a reformulação da noção economicista de qualidade na educação para parâmetros sociais com o propósito de transformar a sociedade, ao invés de manter determinada ordem social. Para a realização 
deste projeto humanista, seria necessário que o currículo transpusesse seu eixo na formação do trabalhador para a formação do cidadão.

O papel da gestão escolar, que agora conta com um aumento das mulheres na docência (Oliveira et al., 2017), continua a ser reconhecido por uma função organizadora semelhante ao da administração escolar, porém pactua-se uma descentralização de poder com vistas a implementar políticas educacionais com a devida atenção ao cotidiano das escolas. Admite-se (ou luta-se para reconhecer) cenários imprevisíveis no ambiente escolar que só podem ser respondidos e decididos por quem vivência o dia a dia nas Unidades Escolares. Certamente, esse deslocamento não seria suficiente para criar uma autonomia plena para as escolas, pois elas continuam sujeitas ao sistema educacional por meio do que Gallo (2018) denominou governamentalidade democrática, ou seja, utilizar políticas públicas de incentivo à cidadania, à inclusão e à diversidade para conduzir as vontades da população de acordo com interesses do Estado, mas sem retirar a liberdade dos sujeitos de decidir como conduzir a si mesmo.

Atualmente, algumas produções científicas que relacionam gestão escolar e gênero sustentam a suficiência dos valores democráticos para diminuir desigualdades de gênero nas escolas', uma vez que estariam comprometidos com uma cultura participativa (Brabo, 2004), com a cidadania (Brabo, 2004; Fialho \& Nascimento, 2017), o respeito às diferenças ou à diversidade (Fialho \& Nascimento, 2017; Silva \& Tunice, 2019), a igualdade de gênero (Marchão \& Bento, 2012; Santos, 2018), o combate à discriminação (Fialho \& Nascimento, 2017; Fiuza, 2013; Santos, 2018) ou a aprendizagem e o conhecimento (Fialho \& Nascimento, 2017; Nascimento \& Silva, 2015).

Esta relação temática torna-se necessária quando percebe-se na gestão escolar uma alternativa para combater desigualdades de gênero, abrangendo os possíveis efeitos do direito à educação aliado a uma gestão democrática. Deste ponto de vista, é esperado de um/a gestor/a escolar, além das funções de administração clássica, as seguintes habilidades: a) formar, incentivar e motivar o corpo docente e discente, conectar-se com suas dimensões humanas e melhorar o clima organizacional da escola; b) pensar o mundo e o contexto escolar por um prisma político, disputar a educação no campo político e criar consciência política na comunidade pela educação; c) romper com tradicionalismos, inovar; d) partilhar o poder do cargo ocupado; e) mediar ações afirmativas e políticas educacionais; f) facilitar a comunicação de segmentos do canal pedagógico; g) ter atitude, método e reflexão pedagógica, além dos conhecimentos burocráticos; h) incluir a diferença ou diversidade enquanto parâmetro de qualidade educacional ${ }^{2}$ para desconstruir ou combater estereótipos e preconceitos.

\footnotetext{
1 Além das produções aqui apontadas, é possível encontrar outras referentes a desigualdades de gênero no acesso ao cargo de gestão, não mencionadas neste artigo.

2 Privilegiando o instrumento da Avaliação Interna.
}

7 - Linhas Críticas, Brasília, DF, v. 26 (2020), p. 7-18 
Essas responsabilidades da gestão escolar que pratica a gestão democrática são defendidas em vários momentos nas produções científicas (Brabo, 2004; Fialho \& Nascimento, 2017; Fiuza, 2013; Marchão \& Bento, 2012; Nascimento \& Silva, 2015; Santos, 2018; Silva \& Tunice, 2019), com argumentações legalistas, ressaltando a comunicação entre o Estado e as Unidades Escolares por referência à CF/88 (Congresso Nacional do Brasil, 1988), à Lei de Diretrizes e Base da Educação Nacional (LDB) (Casa Civil, 1996), aos PCN (SEF, 1997) ou à Declaração Universal dos Direitos Humanos (DUDH) (Assembleia Geral da ONU, 1948). É possível, ainda, duvidar da função pedagógica do tema transversal Orientação Sexual pelos seus objetivos de saúde preventiva (Fiuza, 2013)33, criando grupos de risco como alvos das políticas, embora o mesmo não seja apontado para o tema transversal Cidadania.

Nesse sentido, Brabo (2004, pp. 60, 72) aponta que "embora sejam várias as críticas à LDB, elaborada e aprovada à luz da CF/88, ela garante avanços em relação à questão de se ter uma escola mais democrática e de melhor qualidade", o que inclui "a necessidade de refletir sobre questões essenciais que envolvem a relação entre uma nova sociedade globalizada, um Estado em transformação e os seus reflexos e impactos na questão educacional" para desenvolver um cidadão global. Sobre essas necessidades reflexivas, poder-se-ia presumir a "inserção social e produtiva" de alunos "pautada no respeito ao direito de igualdade e de cidadania reconhecida", assunto que surge em um "século [o XXI] onde o mercado é globalizado e altamente competitivo", devendo as escolas "atender aos anseios e necessidades dos alunos que garantam através da gestão uma contribuição para que as alunas compreendam as questões de gênero" (Fiuza, 2013, pp. 59-60).

Este último exemplo poderia ser traduzido por aprendizagem com foco no aluno, a qual é defendida porque:

[...] a legislação garante o acesso da criança à escola e um currículo que contemple a Base Nacional Comum e essa mesma legislação prima pela formação dos(as) profissionais para zelar por uma educação de qualidade que contemple todas as áreas do conhecimento de acordo com a necessidade apresentada pela demanda discente (Nascimento \& Silva, 2015, pp. 10-11).

Posição expressada também na defesa de Direitos Humanos (Fiuza, 2013; Nascimento \& Silva, 2015; Santos, 2018,), a qual se vale da mediação de conflitos como oportunidade para criar uma "convivência mais saudável" e à "criação da cultura de paz" (Fialho \& Nascimento, 2017, p. 940), cujos incentivos seriam extremamente bem recebidos se a violência produzida pelo Estado policial (Preciado, 2008/2018) não fosse mitigada em prol de soluções individuais para problemas que existem em redes complexas de poder.

\footnotetext{
3 Em Santos (2018), orientação sexual admite tanto a conotação de conceito referente à categoria de análise gênero quanto ao termo popularizado pelos PCN (SEF, 1997) e em outras políticas curriculares.
}

Caballero, A. I. M., Assis, A. E. S. Q. O queer enquanto enfoque zetético... 8 
Esta defesa à cidadania aparece descontextualizada da ética neoliberal que permeia de modo geral as relações sociais ${ }^{4}$. Assim torna-se simples, por um lado, responsabilizar a gestão escolar por suas escolhas de ações, programas, planejamentos, conhecimentos e experiências com o gênero no cotidiano escolar, perdendo de vista contextos mais amplos, incluindo aí governos e governantes (ministros, secretários, conselheiros etc.) na formulação de políticas educacionais (Fialho \& Nascimento, 2017; Fiuza, 2013; Marchão \& Bento, 2012; Silva \& Tunice, 2019). Por outro lado, mesmo quando ressalta-se os conflitos entre diferentes esferas políticas, continua-se a defender políticas de Estado para um "aperfeiçoamento" da democracia (Brabo, 2004; Nascimento \& Silva, 2015; Santos, 2018).

Porém acreditamos que uma interpretação queer é incompativel com princípios de igualdade e diferença se utilizados em perspectiva legalista, como exposto anteriormente. Para demonstrar tal incompatibilidade, iniciamos um breve percurso pela noção de Lei nos Estudos de Gênero, até encontrarmos o desenvolvimento do queer entre as correntes pós-estruturalistas.

\section{A Lei do corpo e a Lei no corpo}

Kelsen (1943/1976), contemporâneo de Viehweg (1953/2008), distingue Direito e Moral, concluindo que o Direito é Moral, mas a Moral não necessariamente é Direito. Ambos teriam interesses em instituir uma norma social para determinar as condutas internas $e$ externas dos sujeitos, variando apenas no uso da coerção física e de instituições centralizadas (caso do Direito) ou através da aprovação/desaprovação advinda de instituições descentralizadas (caso da Moral). Utilizando componentes kelsenianos, podemos dizer que os Estudos de Gênero tiveram a importante tarefa ética de conhecer e descrever um sistema moral corporal predominante, uma espécie de regulação da conduta humana que, por sua vez, estatui um dever-ser a um corpo em face do outro e em face de si mesmo.

A norma moral (no Direito ov em sentido ampliado) vem regular um comportamento social dos indivíduos numa sociedade. Esta prescrição, para os Estudos de Gênero, significa um limite ao corpo, faz com que ele obedeça a uma lei para que esta participe das consciências a elas sujeitas (mesmo contra seus próprios sistemas morais) (Kelsen, 1943/1976). A repetição da sanção a uma proibição corporal determinada estabeleceria a criação de corpos (Butler, 1990/2017), pois entendemos que o fazer corporal aufere corporeidade. Os comportamentos, desde que adequados às normas morais previstas para o corpo, realçariam traços de gênero.

\footnotetext{
${ }^{4}$ Com exceção de Brabo (2004), que não duvida da positividade da cidadania global e também não a exalta.
}

9 - Linhas Críticas, Brasília, DF, v. 26 (2020), p. 9-18 
Assim, descrevemos o processo pelo qual se produz o gênero de um sujeito, seja ele adequado ao sistema moral legítimo (o que tem-se chamado de moral heteronormativa) ou ilegítimo (os valores defendidos pelos movimentos LGBTQI+, os quais caracterizariam condutas morais desestabilizadoras da norma social legitimada). Aqui, coube-nos decidir que todo gênero é perpassado pela interiorização de um valor, cuja expressão em ação/comportamento está validada como norma devido ao entorno social capaz de transformar este gênero em uma atitude moral.

Os Estudos de Gênero 5 trazidos para esta discussão concentram-se numa crítica epistemológica da Lei, denunciando o que se pensava ser uma descrição das experiências de gênero até então construídas pelos sujeitos como, na verdade, uma prescrição da Lei sobre esses corpos (Preciado, 2000/2014), instituindo tabus contra a homossexualidade e o incesto, conquistando algum controle sobre essas subjetividades (Butler, 1990/2017).

O funcionamento prescritivo dessa Lei terá como princípio manter a economia das relações sociais pelas relações sexuais. É o que Rubin (1975/1993) denominou como sistema de sexo/gênero para nos brindar uma explicação das diferenças entre experiências sociais de homens e mulheres (e como estas duas categorias teriam sido importantes nas economias matrimoniais) nas mais diversas sociedades, fossem elas capitalistas ou pré-capitalistas. Lendo O capital, de Karl Marx, Rubin (1975/1993) está interessada em identificar o elemento histórico e moral "que dotou o capitalismo de uma herança cultural de formas de masculinidade e feminilidade" (Rubin, 1975/1993, p. 5) de tal forma que "a análise da reprodução da força de trabalho nem mesmo explica por que são as mulheres quem usualmente realizam o trabalho doméstico em casa, e não os homens" (Rubin, 1975/1993, p. 4).

O que nos interessa nesse artigo de Gayle Rubin é a estreita relação entre direitos e educação que nos aparece como resultado da exegese literária por ela realizada de autores clássicos. Ao interpretar a troca de mulheres como presentes no sistema de parentesco levistraussiano (nem sempre como objetos inanimados, mas objetos dotados de qualidades pessoais), a autora nos conduz a pensar as alianças criadas entre os homens pela exogamia como uma conduta moral que proporciona coesão social, estratégia por ela mencionada como anterior ao surgimento do Estado.

Essas relações de troca permitem a Gayle Rubin recapitular como a repressão psíquica do Complexo de Édipo, a partir das "descrições" psicanalíticas de Freud, age em homens e mulheres "de seu embate com as normas e regulamentos da sexualidade das sociedades em que nasceram" (Rubin, 1975/1993, p. 13), provocando ressentimento nas meninas ao serem espoliadas no processo de castração, pois o falo roubado não seria devolvido, enquanto os meninos devem ser pacientes e esperar para trocar o falo por uma mulher

\footnotetext{
5 Particularmente os estudos que mantém proximidade com as escolas freudiana e lacaniana de psicanálise e com as contribuições antropológicas de Lévi-Strauss sobre as relações de parentesco.
} 
quando chegada a hora. Logo, seu intuito está em ensaiar a transformação da norma social em norma psíquica através do controle social da conduta individual, reafirmando uma conduta psíquica de um sujeito.

O cuidado de Gayle Rubin em não reproduzir isto que denominamos Lei (as estruturas das relações de parentesco e o Complexo de Édipo) está na forma como compreende as crianças:

Cada criança contém todas as possibilidades sexuais disponíveis à expressão humana. Mas em qualquer sociedade, apenas algumas possibilidades serão expressas, enquanto que outras serão contidas. Quando a criança deixa a fase edipiana, sua libido e identidade de gênero já têm sido organizadas em conformidade com as regras da cultura que a está domesticando (Rubin, 1975/1993, p. 16).

O direito, aqui resumido à moral, "confunde-se com as maneiras características de agir de um povo" (Ferraz Jr., 1968/2003, p. 53), isto é, determina a educação das crianças. Mesmo quando o direito amplia-se na forma de um Estado, preserva estes preceitos morais de funcionamento psíquico por controle dos direitos dos seus cidadãos. Beauvoir (1949/2016) expõe demoradamente como o direito à herança e à propriedade esteve historicamente destinado aos homens. A filósofa descreve que, em vários momentos da história das mulheres, inclusive as mais abastadas, foram impostos limites jurídicos para usar suas riquezas, chegavam a ter tutores para administrar bem esse dinheiro quando não estavam comprometidas em um matrimônio. No fim das contas, estas medidas institucionais funcionavam para evitar maus gastos de uma opulência reservada aos maridos ou filhos.

Como estratégia ideológica, esses legisladores faziam crer que suas leis eram Direito (Lyra Filho, 1982), assim exerciam sua dominação sobre as mulheres no curso da história. Este tipo de controle social realizado pelos homens sobre as condutas individuais das mulheres através da violência simbólica do Estado é denominado patriarcado por algumas vertentes dos Estudos Feministas ${ }^{6}$. Este tipo de opressão, iniciada na infância pela educação, e prosseguindo na vida adulta, pela coerção jurídica, constitui no capitalismo herança de costumes pré-capitalistas, como trataram de demonstrar Gayle Rubin e Simone de Beauvoir, o que indica um problema de agência mais do que uma continuidade de atitudes e de violências que nos permitiria trabalhar com a "história como um todo" (Scott, 1986/1995).

Nesta interface, convém preparar o terreno da interpretação histórica dos corpos subjugados por regras e normas das mais variadas naturezas e assim naturalizadas para examinar "não o que o homem pensa sobre o Direito, mas do que juridicamente ele faz" (Lyra Filho, 1982, p. 29), uma vez que, enquanto seja também Moral a norma, é capaz de adentrar os corpos independentemente da vontade dos sujeitos para participar de suas ações, não raras vezes com a função de fazer o sujeito pensar que sua conduta é reflexo

\footnotetext{
${ }^{6}$ Rubin (1975/1993) e Scott (1986/1995) desincentivam o uso de patriarcado para estudar a dominação masculina e a história das mulheres devido a seu caráter universalista, enquanto Saffioti (2004) o recupera para diferenciar violência de gênero e violência contra a mulher.
}

11 - Linhas Críticas, Brasília, DF, v. 26 (2020), p. 11-18 
de seu desejo, como apontou Michel Foucault em sua célebre História da Sexualidade (1976/2015). Sendo assim, existe um princípio arbitrário da imposição da norma e outro princípio que oculta esta arbitrariedade do corpo por ela produzido, uma dupla violência contra os sujeitos (Bourdieu, 1998/2001) que faz aparecer a Lei no corpo como a Lei do corpo - a naturalização da Moral.

Cabe-nos perguntar se o Direito, que nunca deixa de ser Moral, é capaz de diferenciar esses dois tipos de Leis. Este parece ter sido um dos principais questionamentos feministas ao Estado democrático, dotado de poder para impor a Lei ou a norma, o que já guarda em si uma negatividade no sistema de representação, distância entre os representantes e o povo (Habermas, 1996/2002). Todavia, ainda que a diferença entre Direito e Moral seja de conhecimento da luta e ética feminista (nem sempre com estes mesmos termos), a liberdade sexual e material do gênero mulheres pretende ser alcançada, não raras vezes, com um feminismo de Estado (Preciado, 2008/2018), cuja característica principal é encaminhar suas vontades ao Estado para que sejam acatadas (punições para violência doméstica, liberalização do aborto, educação sexual e de gênero nas escolas etc.) e, ao verem a concretização desses desejos, permitir-se ser governado por essa Moral que agora é Direito.

O que nos leva ao seguinte questionamento: por que o princípio da diferença recorre às vontades do Estado e não à comunidade escolar para justificar seus fins? O queer surge exatamente para desconfiar de que o feminismo de Estado é uma alternativa para trazer justiça e liberdade, pois uma vez transformadas as demandas de um povo em dispositivos jurídicos ou políticas públicas a partir dos mecanismos existentes, permite-se ao Estado o controle jurídico de gêneros, o que significa amparar-se legitimamente para distribuir desigualmente a vulnerabilidade entre a população (Butler, 2015/2018).

Ressurge, então, o dissenso entre Direito e Moral e a oportunidade de que uma nova Moral ganhe o estatuto naturalizado de Lei. Com efeito, esse princípio da diferença é uma recomendação para interpretar o direito à educação, a localidade do poder poderia prevalecer sobre as forças centrípetas que encontram no Estado sua razão de ser, pois o queer, enquanto representação radical da diferença, promete descentralizações morais em relação à naturalização da Lei. É por esta via que recordamos com Louro (2012) como - campo educacional exibe saberes e disposições políticas disciplinadoras, normalizadoras, regradas, obedientes e prescritivas, ao passo que o queer aparece como a negação destas posições, a partir das quais a autora pergunta "como é que o queer pode entrar no currículo [uma vez que institucionalizado deixa de ser queer, pois não está mais em movimento]?" (Louro, 2012, p. 366). Este paradoxo, proposto como um entrave educacional, também é um entrave jurídico, visto que o direito à educação também é um direito à diferença que requer alguma igualdade na forma do currículo (Cury, 2002). 
A própria ideia de qualidade em educação persiste por um currículo da cidadania que não seria aceitável (sem problemas), com algumas educações de gênero, como uma pedagogia queer em desacordo com sistemas globais de produção, com valores neoliberais e com a própria figura do Estado como representação legítima das vontades da população, geralmente compreendidas pela ideia de biopolítica (Butler, 1990/2017; Foucault, 1976/2015; Preciado, 2008/2018), a partir da qual o Direito expressa a Moral de governantes comprometidos com ideias economicistas e nacionalistas. Isto é, Estados pautam-se em conduzir as diferenças para um governo do igual, cuidados governamentais necessários para trazer ordem e progresso sem encontrar resistências.

Esses questionamentos queer possuem a função de balancear a interpretação dogmática da prescrição e da presunção (atitudes interpretativas) com o enfoque zetético queer. A partir da descrição de Ferraz Jr. (1968/2003, p. 40), "um [o direito dogmático] ao partir de uma solução já dada e pressuposta, está preocupado com um problema de ação, de como agir. Outro [o direito zetético], a partir de uma interrogação, está preocupado com um problema especulativo, de questionamento global e progressivamente infinito de premissas". Em outros termos: agora compreendemos que o queer é sempre uma pergunta das certezas mais evidentes, não um currículo para a cidadania. E mais do que uma vertente filosófica dos Estudos de Gênero, parte de uma história de violações que sempre tiveram a figura do Estado como um impedimento para a realização de projetos pessoais de segmentos populacionais que conduziam seu próprio gênero em desvio para com a Lei.

O educador dogmático arrisca-se a contribuir com exclusão e marginalização de sujeitos queer pautando-se na força da Lei, confia no discurso constitucional como se representasse sua Moral, ignorando que a LDB é resultado de confrontações na arena política. Ela torna-se uma "carta de intenções" (Saviani, 1997/2016) pela necessidade de adiar as bases curriculares para um momento em que o movimento conservador teria suas pautas aprovadas. Os PCN foram orientações gerais que satisfizeram o espírito democrático como incentivo ao princípio da diferença, o qual procurou melhorar políticas de diversidade sexual, materiais didáticos, formação de professor(as) e assim por diante. Estes acontecimentos pertencem ao final da década de 1990 e durante a década de 2000 .

Somente na década de 2010 emerge o que Rolnik (2018) identificou como sendo uma aliança entre forças neoconservadoras e neoliberais com poder político para recuperar com avidez a pretendida base curricular do fim do século XX, sendo a Base Nacional Comum Curricular (BNCC) (Secretaria de Educação Básica, 2017) o resultado dessa oportunidade histórica de exibir por meio de conhecimentos práticos e universais compromissos com um neoliberalismo normativo (Macedo, 2016), repleto de heteronormatividade, colonialismo e empreendedorismo. 
O que não significa a impossibilidade de ressignificação do sentido de cidadania, mas uma demora nos sentidos que o termo implica para a organização das escolas. Quem se beneficia com esses sentidos? Como são partilhados no cotidiano escolar? Que diferenças ela exclui, marginaliza ou silencia? Que igualdades são incluídas, cuidadas e acolhidas? Ou ainda, para ser mais imediato, por que é tão comum o Estado não mediar violências de gênero nas escolas a partir de premissas pedagógicas e tentar criminalizar, patologizar ou exorcizar o queer? Estas precauções servem para evitar a centralização de gestões que se dizem democráticas em um Estado neoliberal afeito pela privatização dos desejos de seus cidadãos, isto é, preparado para governar.

Se o princípio é o entendimento que guia uma compreensão sobre uma regra, então a radicalização de um princípio da diferença só pode significar a suspeita para com o Estado ao nível das regras, dos signos, discursos e práticas de governança. Numa zetética queer, questionar princípios é utilizar-se da dúvida como recurso desconstrutivo para problematizar e investigar as formas de governo sobre os corpos, compreender em que medida as reinvenções dessas formas de governo são necessárias ou suficientes e 0 quanto partilham das motivações éticas de seus intérpretes para a gestão de uma escola. Assim, educadoras(es) ressignificam as relações democráticas de uma escola ao deslocar seus sentidos de uma compreensão majoritária pautados na centralidade do Estado para uma compreensão minoritária que faz da vontade do povo (e não da população) a interpretação apropriada para se combater desigualdades de gênero nas escolas.

\section{Conclusão}

Certamente, há uma distância entre sistemas educacionais e sistemas escolares para a qual não há sincronização e ressonâncias de vontades perfeitas (Ball, 1994). É na distância mantida entre cotidianos, da materialidade da vida ou das condições de existência que a problematização de normas de gênero ganha sua relevância com a dispersão de sentidos ao invés de sua fixação. Neste eterno movimento de descontruir o direito e de concretizar políticas, o direito à educação tem espaço para ação e experimentação de novas formas jurídicas, pois a premissa menor (crianças transgênero nas ou fora das escolas) contribui para deslocar a premissa maior (o direito à educação que conduz o sistema educacional) por meio do estranhamento ou aceitação de uma escola, seja na centralização ou descentralização das decisões pela gestão escolar.

Esta desconstrução da unidade discursiva do direito à educação exibe desde já uma dupla importância: 1) contrariar a interpretação legalista de que o discurso à cidadania vale para toda a população por confiar no texto de documentos oficiais sem questionar as movimentações políticas, chegando a tomar o sentido do texto como universal ou eterno; e 2) em decorrência do ponto anterior, cultivar nos sujeitos queer uma vontade de reconhecimento para uma instância preparada politicamente a negar-lhes direitos 
fundamentais quando não correspondem ao ideal de cidadão. Aqui iniciamos uma desconfiança para com as políticas de Estado, o qual toma para si o esforço político e voluntário de indivíduos e grupos na universalização de regras e princípios morais que, por sua própria natureza extensiva, tendem a fazer as diferenças desaparecerem sob o aspecto do igual, seja por controle, disciplina ou extermínio de corpos perversos à democracia (Pinheiro, 2018).

Por isso relembramos que a Moral precede o Direito. A justiça para a população queer nas escolas requer conhecer o gênero nos cotidianos escolares pelas condutas e pelos sentidos que atravessam esses espaços antes da defesa ferrenha aos direitos à educação. A localidade constitui, portanto, o fundamento na proposta de Louro (2004) por um "currículo provisório" e não pela base nacional comum, já que Direito não é sinônimo de Justiça (Lyra Filho, 1982). Acredita-se que o incentivo à autoexperimentação (Preciado, 2008/2018) nas experiências de gestão ofereça os desvios necessários à governamentalidade democrática (Gallo, 2018).

\section{Referências}

Assembleia Geral da ONU. (1948). "Declaração Universal dos Direitos Humanos", resolução 217 A. Organização das Nações Unidas. https://www.un.org/en/universaldeclaration-human-rights/

Assis, A. E. S. Q. (2012). Direito à educação e diálogo entre poderes [Tese de doutorado, Universidade Estadual de Campinas]. Repositório da Produção Científica e Intelectual da UNICAMP. http://repositorio.unicamp.br/jspui/handle/REPOSIP/250736

Ball, S. (1994). Education reform: a critical and post-structural approach. Open University Press.

Beauvoir, S. (2016). O segundo sexo (3a ed.). Nova Fronteira. (Trabalho original publicado em 1949).

Bourdieu, P. (2001). Meditações pascalianas. Bertrand Brasil. (Trabalho original publicado em 1998).

Brabo, T. S. A. M. (2004). Democratização da escola sob uma perspectiva de gênero: um novo desafio. ORG \& DEMO, 5(1), 55-78. https://doi.org/10.36311/1519-

$0110.2004 . v 5 n 1.421$

Butler, J. (2017). Problemas de gênero: feminismo e subversão da identidade. Civilização Brasileira. (Trabalho original publicado em 1990).

Butler, J. (2018). Corpos em aliança e a política das ruas: notas para um teoria performativa de assembleia. Civilização Brasileira. (Trabalho original publicado em 2015).

Caballero, A. I. M. (2020). A máquina binária do Estado: do desejo da política à política do desejo. Linha Mestra, (41). https://doi.org/10.34112/1980-9026a2020n41p55-64 
Casa Civil. (1996). Lei no 9.394, de 20 de dezembro de 1996, que estabelece as diretrizes e bases da educação nacional. República Federativa do Brasil. Presidência da

República. http://www.planalto.gov.br/ccivil_03/leis/19394.htm

Congresso Nacional do Brasil. (1988). Constituição da República Federativa do Brasil de 1988. República Federativa do Brasil. Assembleia constituinte.

http://www.planalto.gov.br/ccivil_03/constituicao/constituicao.htm

Cury, C. R. J. (2002). Direito à educação: direito à igualdade, direito à diferença.

Cadernos de Pesquisa, 116, 245-262. https://doi.org/10.1590/S0100-15742002000200010

Dias Jr., A. C., \& Caballero, A. (2020). Questões de gênero na Aprendizagem ao Longo

da Vida. Revista PLURAIS, 5(1), 220-240. http://doi.org/10.29378/plurais.2447-

9373.2020.v5.n1.193-219

Ferraz Jr., T. S. (2003). Introdução ao estudo do direito: técnica, decisão, dominação (4 ${ }^{a}$ ed.). Atlas. (Trabalho original publicado em 1968).

Fialho, L. M. F., \& Nascimento, L. B. S. (2017). O que os gestores escolares da rede pública entendem sobre gênero?. RPGE, 21 (esp.2), 927-945.

https://doi.org/10.22633/rpge.v21.n.esp2.2017.10147

Fiuza, A. S. (2013). Gênero na Educação de Jovens e Adultos, um desafio para a gestão escolar [Dissertação de Mestrado, Universidade Federal de Santa Maria]. Repositório Digital da UFSM.

https://repositorio.ufsm.br/bitstream/handle/1/1011/Fiuza_Adriane_dos_Santos.pdf?se quence $=1$

Foucault, M. (2015). A história da sexualidade 1: a vontade de saber (2a Ed.). Paz e Terra. (Trabalho original publicado em 1976).

Gallo, S. (2018). Políticas da diferença em políticas públicas em educação no Brasil. Educação e Filosofia, 31 (63), 1497-1523. https://doi.org/10.14393/REVEDFIL.issn.01026801.v31n63a2017-10

Gomes, J. V. (2011). Juristas, magistrados e advogados - grupos à parte?. In: Ensaios

CAIS: Fraternidade - Justiça, bem comum, economia e felicidade (pp. 56-65).

Padrões Culturais Editora.

Habermas, J. (2002). A luta por reconhecimento no Estado Democrático de Direito. In: A inclusão do outro: estudos de teoria política (pp. 229-255). Loyola. (Trabalho original publicado em 1996).

Kelsen, H. (1976). Teoria Pura do Direito. Armênio Armando. (Trabalho original publicado em 1943).

Louro, G. L. (2001). Teoria quer - uma política pós-identitária para a educação. Revista Estudos Feministas, 9, 541-553. https://doi.org/10.1590/50104-026X2001000200012

Louro, G. L. (2004). Um corpo estranho: ensaios sobre sexualidade e teoria queer. Autêntica.

Louro, G. L. (2012). Os Estudos Queer e a educação no Brasil: articulações, tensões, resistências. Contemporânea, 2, 363-369.

https://www.contemporanea.ufscar.br/index.php/contemporanea/article/view/87/5 $\underline{2}$

Caballero, A. I. M., Assis, A. E. S. Q. O queer enquanto enfoque zetético... 16 
Lyra Filho, R. (1982). O que é direito? Brasiliense.

Macedo, E. (2016). As demandas conservadoras do movimento Escola Sem Partido e a

Base Nacional Comum Curricular. Educação \& Sociedade, 38(139), 507-524.

http://doi.org/10.1590/ES0101-73302017177445

Marchão, A. J., \& Bento, A. (2012). I. Promoção da igualdade de gênero - um estudo em contexto de educação pré-escolar. In: III Seminário de I\&DT, Centro Interdisciplinar de Investigação e Inovação do Instituto Politécnico de Porto Alegre.

Nascimento, A. V, \& Silva, M. L. S. (2015). Sexualidade na escola - o olhar da gestão escolar nas séries finais do ensino fundamental nas escolas de Lagoa de Dentro - PB. In: II CONEDU, Campina Grande.

https://editorarealize.com.br/editora/anais/conedu/2015/TRABALHO_EV045_MD1_SA1 1_ID3534_15082015210142.pdf

Oliveira, D. A., Duarte, A. W. B., \& Clementino, A. M. (2017). A Nova Gestão Pública no contexto escolar e os dilemas dos(as) diretores(as). RBPAE, 33, 707-726.

https://doi.org/10.21573/vol33n32017.79303

Pinheiro, D. (2018). Autoritarismo e homofobia: a repressão aos homossexuais nos regimes ditatoriais cubano e brasileiro (1960-1980). Cadernos PAGU, 52, e185213.

http://doi.org/10.1590/18094449201800520013

Preciado, B. (2014). Manifesto contrassexual: práticas subversivas de identidade sexual.

$\mathrm{N}-1$ edições. (Trabalho original publicado em 2000).

Preciado, B. (2018). Testo Junkie: sexo, drogas e biopolítica na era farmacopornográfica.

$\mathrm{N}-1$ edições. (Trabalho original publicado em 2008).

Ramalho Jr., A. (2012). Neoliberalismo empírico. In: Dicionário de políticas públicas C. L. F.

Castro; C. R. B. Gontijo, Amabile; A. E. N. Amabile (Orgs.). EdUEMG, 352-357.

Rolnik, S. (2018). Esferas da insurreição: notas para uma vida não cafetinada. N-1 edições.

Rubin, G. (1993). O tráfico de mulheres: notas sobre a "economia política" do sexo.

Edição S.O.S Corpo. (Trabalho original publicado em 1975).

Saffioti, H, I. B. (2004). Gênero, patriarcado e violência. Fundação Perseu Abramo.

Santos, E. S. (2018). (Des)respeito à diversidade sexual e à diversidade de gênero em escolas de Caruaru - PE: a questão da LGBTfobia e os enfrentamentos e/ou silenciamentos da Gestão Escolar [Dissertação de Mestrado, Universidade Federal de Pernambuco]. Repositório Digital da UFPE.

https://repositorio.ufpe.br/handle/123456789/29691

Saviani, D. (2016). A lei da educação: LDB - trajetória, limites e perspectivas (13 ${ }^{a}$ ed.).

Autores Associados. (Trabalho original publicado em 1997).

Scott, J. (1995). Gênero: uma categoria útil para análise histórica. Educação \&

Realidade, 20(2), 71-99. (Trabalho original publicado em 1986).

https://seer.ufrgs.br/educacaoerealidade/article/view/71721/40667

Secretaria de Educação Básica (2017). Base nacional comum curricular. Ministério da Educação. 
http://basenacionalcomum.mec.gov.br/images/BNCC_EI_EF_110518_versaofinal_site. pdf

Secretaria de Educação Fundamental (SEF). (1997). Parâmetros curriculares nacionais: introdução aos parâmetros curriculares nacionais. Ministério da Educação. http://portal.mec.gov.br/seb/arquivos/pdf/livro01.pdf

Silva, B. O., \& Tunice, L. M. L. (2019). O papel da Gestão Escolar na tratativa de demandas relacionadas a problemas de Identidade de Gênero na Educação Básica. ECCOM, 10(20), 183-190.

http://unifatea.com.br/seer3/index.php/ECCOM/article/view/1069

Silva, V. A., \& Wang, D. W. L. (2010). Quem sou eu para discordar de um ministro do STF? $O$ ensino do direito entre argumento de autoridade e livre debate de ideias. Revista Direito GV, 6, 95-118.

https://bibliotecadigital.fgv.br/ojs/index.php/revdireitogv/article/view/24210/22983

Simioni, R. F. (2015). Interpretação jurídica e percepção seletiva: a dimensão organizacional da produção de sentido no direito. Revista Brasileiro de Direito, 11 (1), 135-147. https://doi.org/10.18256/2238-0604/revistadedireito.v1 ln1p135-147

Vianna, C. (2018). Políticas de educação, gênero e diversidade sexual: breve histórico de lutas, danos e resistências. Autêntica Editora.

Viehweg, T. (2008). Tópica e Jurisprudência: Uma contribuição à investigação dos fundamentos jurídicos-científicos. Sergio Antonio Fabris Editor. (Trabalho original publicado em 1953).

\section{Biografia}

\section{Alan Isaac Mendes Caballero}

Mestrando em Educação pela FE/UNICAMP e associado ao Grupo de Estudos e Pesquisas em Políticas Públicas (GPPES), Educação e Sociedade, atualmente pesquisa temas relacionados à gestão escolar, currículos de gênero e políticas de diversidade.

E-mail: alanisaac09@gmail.com

ORCID: https://orcid.org/0000-0003-1270-0971

\section{Ana Elisa Spaolonzi Queiroz Assis}

Doutora em Educação pela FE/UNICAMP e associada ao Laboratório de Políticas Públicas e Direitos Fundamentais (LabDir) e ao Laboratório de Políticas Públicas e Planejamento Educacional (LaPPlanE), atualmente pesquisa os seguintes temas: educação ambiental, pobreza multidimensional, direito à educação e formação de professores.

E-mail: anasqa@unicamp.br

ORCID: https://orcid.org/0000-0003-3759-4845 